\title{
Familiarity with Measures to Reduce Administrative Burdens in The Public and Private Sector in Slovenia
}

UDK: 658:35(497.4)

Urška Milavec

urskamilavec1@gmail.com

Maja Klun

University of Ljubliana, Faculty of Administration

maja.klun@fu.uni-li.si

\section{ABSTRACT}

Measures to reduce administrative burdens are part of efforts to improve regulation quality. The aim of the research carried out in 2010 in the public and private sector was to determine whether their staff display different levels of familiarity with the measures and whether both sectors define the same groups of regulation as the most burdensome. The results indicated that information provision on measures to reduce administrative burdens in Slovenia is poor, particularly in the private sector, which is intended as the main beneficiary of these measures. Despite this, the private sector reported that regulation for small and medium-sized businesses had improved over the period in which measures to reduce administrative burdens had been implemented. The public sector assessed public procurement regulation as the most burdensome, while the private sector ranked employment regulations as the most burdensome.

Key words: administrative barriers and burdens, administrative costs, competitiveness, information provision, public and private sector, Slovenia

JEL: H83, K2, K3 
Urška Milavec, Maja Klun

Familiarity with Measures to Reduce Administrative Burdens

in The Public and Private Sector in Slovenia

\section{Introduction}

The concept of regulation in its broadest sense indicates the methods used to arrive at and implement decisions of public significance. The most general concept of regulation defines it as the achievement of public sector objectives through the application of rules or standards (Hood et al., 2000). When regulation has effects that exceed the public purpose one can talk of administrative barriers. The first measures in the field of reducing administrative burdens (RAB) in Slovenia started in 2000, with the so-called "anti-bureaucracy programme". The measures were a logical consequence of a series of actions and research that appeared around the world at that time. In addition to the OECD and the European Commission, many other groups were also active, such as the Dutch SCM Network (an international group operating in the field of exchanging best practice in order to reduce the administrative burden and eliminate unnecessary bureaucracy), and a network of senior officials working in the field of improving their countries' legal systems who created a forum to exchange best practice in writing new regulations (primary and secondary legislation). The most prominent research into administrative burdens has been carried out by the European Bank for Research and Development Bank (the BEEPS - Business Environment and Enterprise Performance Survey), the World Bank (WGI - Worldwide Governance Indicators), the IMD World Competitiveness Yearbook ranking from Switzerland's International Institute for Management Development, the OECD research into the institution quality and administrative costs (OECD, 2001) and a number of other partial research in this field (Radaelli \& DeFrancesco, 2007; Brunetti et al., 1998; Chittenden et al., 2003; Massey, 2003). Common to all these studies is the finding that institutional and regulatory quality has a significant impact on business and economic competitiveness.

As stated, the first measures in Slovenia were introduced as part of an anti-bureaucracy programme. The first report on the simplification of regulations was published in 2005. This was followed by an action plan entitled Programme of Measures to Eliminate Administrative Burdens, which was presented annually on the government's website. The 2005 report presented 40 measures, which were not financially evaluated. Progress was demonstrated in the 2006 report, in which some of the measures were financially evaluated (e.g. local communities' annual saving on various public services, as well as the fact that certification by 
administrative offices was made equal to that of a notary public for certain documents). The 2006 Action Plan included 34 measures $(92 \%$ of measures had been realised by October 2008), in 2007 there were 30 measures (60\% realised by October 2008), particularly in the field of "life events", which are important to businesses and individuals. The EMMAS (Standard Methodology for Measurement of Administrative Costs) was finally developed at the end of July 2007. A report published in 2008 provided an overview of measures implemented from 2006 to 2008 and gave an overall assessment of administrative cost savings as measured by the EMMAS methodology for most measures. The measurements indicate that the implementation of measures achieved savings or standardisations of over 100 million euros (e.g. in the fields of business registration at One-Stop-Shops - over 10 million euros were saved annually, data protection procedures were simplified for small businesses - saving of 36 million euros annually, and the abolition of craft/small business permits for over 60 economic activities). In 2008 all 44 measures adopted were realised. The first section of the Action Plan approved by the Government in May 2009 (adopted on the basis of an international commitment that Slovenia, along with other EU members, would reduce the administrative burden by $25 \%$ by 2012 ) included 41 fast-track measures in various fields (employment, taxation, environment), which were the result of suggestions from citizens, business people, and various representative chambers (Ministry of Public Administration, 2009), while the second section included systematic measurements of administrative costs for selected regulations using the standard methodology based on the Standard Cost Model (SCM). In June 2010 the Slovenian Government adopted the Action Plan to Reduce Procedures and Eliminate Administrative Burdens, which focused on six areas of legislation (acquiring a building permit, employment law, payment of taxes and contributions, ownership transfer, international transactions, and implementation of contracts).

Specific focus was placed on Regulatory Impact Analysis (RIA), which Slovenia introduced to its legal regime, at least formally, in 2007 (amendment to Article 8 of the Rules of Procedure of the Government of the Republic of Slovenia - Official Gazette of the Republic of Slovenia, nos 43/2001, 21/2007). It sets out the legal aspects of regulatory impact analysis since 2002. In 2007 the OECD reported that Slovenia had demonstrated major improvements in the reduction of administrative burdens, but stated that its regulatory impact analysis had to improve. The 
Urška Milavec, Maja Klun

Familiarity with Measures to Reduce Administrative Burdens

in The Public and Private Sector in Slovenia

Human Rights Ombudsman made a similar point in a report. In November 2009 the Slovenian parliament adopted the Resolution on Regulatory Work (OGRS, no. 95/2009), a programming act that represents a politically-binding document prepared in line with existing legal regulations defining the procedure for amending regulations. The Resolution relates to the broader field of regulatory work, as performed by the government, ministries and other agencies (holders of public authorisations and local community bodies) as a whole. The Resolution summaries the established constitutional, systemic legal and technical regulatory principles and rules, and also represents a commitment by all political authorities and civil servants to respect the main principles of good legislative policy in policy-making and the preparation of regulations. Those writing regulations and policy should conscientiously analyse the impact of proposed regulations and policies on the economy, environment, social welfare and public finances or the broader public administration, and in line with minimum recommendations and guidelines, cooperate with specialists and the general public. In June 2010 an amendment to the government rules of procedure was adopted on the basis of the Resolution, along with instructions on the preparation of material for the government. To ensure that the programme to eliminate administrative burdens and reduce the administrative burden is effective, these instructions required a regulatory impact analysis of all new or amended regulations. Ministries and similar bodies must therefore pay close attention to this impact analysis and the definition of potential effects on individual areas, including clear definition of the positive or negative impact on the administrative burden.

The above makes clear that most research has focused on measuring the administrative costs of regulation and hence finding the most burdensome factors within individual regulations and seeking possibilities for simplification. Some research, however, defines the most burdensome regulation in terms of economic competitiveness and ranked countries accordingly. The success of various measures is usually indicated by a country's rise up various ranking systems, and more specifically within the reports produced in such countries on the regulatory simplification they have attempted and achieved.

The paper highlights a different aspect, which is not often featured in the research, which is a target population's knowledge of or familiarity with achievements and measures in the field of reducing administrative 
burdens. Two hypotheses were tested in the research. The first was that familiarity with the reducing administrative burden project (RAB) does not differ in the public and private sector. The second hypothesis is that the public and private sector perceive the burden of individual areas of regulation differently. This was intended to assess the effectiveness of RAB measures. This means that if the measures are not actually perceived in practice, they have not been sufficiently well targeted. The target population was divided into two groups: the public and the private sector. The following chapter addresses the findings of various authors and research on the correlation between regulatory quality and economic competitiveness. The definition of the research, the methodology and the results follow.

\section{Significance of reducing administrative burdens to economic competitiveness}

At the Spring Summit in March 2000 the EU heads of government and state adopted the Lisbon Strategy, which set the EU the objective of becoming the most dynamic, competitive and knowledge-based economy in the world by 2010. Improving business competitiveness is also one of the basic objectives of Slovenian development strategy (Slovenian Government, 2010). As part of a "new start for the Lisbon Strategy", the Council of the European Union published a note in March 2005 on broad guidelines for economic policy and emphasised a special guideline (no. 14) on legislation quality, the systematic assessment of administrative costs and benefits, and the reduction of administration burdens on businesses (Council of the European Union, 2005, pp. 23-24). The objectives of the guideline were to create a more competitive business environment and to promote private entrepreneurship through better regulation. Four years previously (2001) the executive summary of the Mandelkern report (a plan for a better legal system compiled by public administration ministers) stated that "improving the quality of regulation is a public good in itself, enhancing the credibility of the governance process and contributing the welfare of citizens." The project to reduce administrative burdens and bureaucratic procedures and the planned reduction in the administrative burden, primarily for business, is a key element in these efforts, as it saves businesses and individuals in the member states from excessive regulation and bureaucracy, and liberates 
Urška Milavec, Maja Klun

Familiarity with Measures to Reduce Administrative Burdens

in The Public and Private Sector in Slovenia

people's energy for entrepreneurship, innovation and citizen involvement (Mandelkern, 2001).

At the EU level activities are directed towards "cleaning-up" existing regulations and improving procedures for new regulations. The cleaning of old regulations has taken place within two projects. The first entailed the simplification of regulations, the second the reduction of administrative burdens (elimination of administrative burdens). The aim of both projects was to simplify and, above all, de-bureaucratise the legislative environment and contribute to cost reduction. Special emphasis is placed on small businesses, and particularly those at the micro-level within that group (Zatler, 2009).

Regulatory quality includes the development of better non-regulatory instruments and greater transparency (Klun \& Slabe-Erker, 2009). The term "better regulations" includes a series of public policy measures aimed at strengthening institutional capabilities to ensure higher quality regulatory provision (Radaelli, 2007; Virant \& Kovač, 2010; Virant, 2010). The summary of the Mandelkern report (2001) states that implementing the Action Plan and other measures significantly contributes to increasing the competitiveness of the European economy, citizen welfare, and government credibility. The OECD report (1997) presented "new methods" of regulation, such as cost efficiency, public participation, bottom-up approach, flexibility, dynamism, responsiveness, etc.

Regulation should never be an end in itself, but must always be a means of protecting the public interest or achieving public objectives. In recent decades the regulatory system in many countries has become more complex, with companies and individuals failing to understand the logic of many regulations. As stated, regulations frequently require numerous forms to be completed that are sometimes unnecessary, time-consuming and expensive. Every country has a need to create the best possible conditions for transactions between business and central government. The country must therefore create some kind of balance (SCM Network, 2010). In practice in Slovenia regulation contains considerable amounts of cross-referencing of other articles and regulations. For example, in the field of tax legislation the ignominious record-holder is the Income Tax Act (OGRS, no. 117/2006), which in just three paragraphs on averaging income includes references to 25 articles of the same act, many of which contain further references (cascading references). 
The European Commission (2009a) published rules on writing regulations, which requires that:

- they are clear, understandable, simple, unambiguous

- they primarily use expressions that are also used in spoken language

- the terminology should be coherent, with the same terms in related legislation having the same meaning

- references to other regulations should be minimal, and crossreferencing should be avoided (article to article).

The most developed EU states launched projects to reduce administrative burdens and simplify the legislative environment well before the European Commission. The Netherlands developed a methodology for measuring administrative costs (SCM), and in 2005 this was adopted by the European Commission for work on reducing administrative costs. Important work took place in the UK and Denmark as well as the Netherlands. The adoption of the 25\%-Reduction Action Plan at the EU level launched a wave of activities in other member states. Administrative costs were estimated at 16.4 billion euros per year in the Netherlands. That figure was $3.6 \%$ of GDP. In Denmark the total sum of administrative burden was estimated at approximately 4.5 billion euros, which was the same as $2.4 \%$ of GDP (SCM Network, 2010). In Slovenia the figure was $4.1 \%$ of GDP, which affected the economy's competitiveness. If the RAB project was implemented in full, the total saving for the economy would be worth 2 to $3.5 \%$ of Slovenia's GDP (Zatler, 2009). That is the main reason it is vital for governments to focus on reducing administrative costs for businesses and individuals. The economic perspective therefore emphasises efficiency and effectiveness with minimal funds (costs). Economically, the reduction of administrative burdens is vital for economic competitiveness, as it enables the use of funds for innovation, consolidates competitiveness and improves economic efficiency and effectiveness. Some empirical attempts have demonstrated the positive impact of regulatory quality on economic growth, measured by GDP per capita (Jalilian et al., 2007).

The Commission has also launched a pan-European project (less bureaucracy) to make businesses in the EU more competitive. From just 7 member states at the end of 2006, now all 27 have defined ambitious objectives to reduce burdens arising exclusively from national regulations. 
Urška Milavec, Maja Klun

Familiarity with Measures to Reduce Administrative Burdens

in The Public and Private Sector in Slovenia

Actions to reduce burdens at the national level are vital, as otherwise the common European objective cannot be achieved. Activities by the EU and individual member states are proceeding in various areas. On one hand therefore measures are being implemented to amend existing legislation, as part of a project to reduce administrative burdens and eliminate administrative barriers in individual priority areas, while on the other hand actions are taking place relating to the systematic measurement of administrative costs and verifying legislation during procedures to adopt it (European Commission, 2010). The Commission has already defined the possible financial outcome of reducing the burden. The measures approved and some already implemented (48 measures $=6 \%$ ), would bring a reduction of 7.6 billion euros. The measures proposed by the Commission (18 measures $=25 \%$ ), could lead to 30.7 billion euros in savings. The preparatory work for further reductions of administrative burdens could lead to the proposal of other 31 measures (2\%), which would mean further savings of at least 2.1 billion euros. In total this would mean a reduction in administrative burden worth 40.4 billion euros of an estimated 123.8 billion euros. That would be a $33 \%$ reduction in the total estimated administrative burden of European legislation (European Commission, 2009b, p. 6).

\section{Presentation of research}

\subsection{Presentation of questionnaire and sample}

The research carried out in Slovenia is presented below. Abroad there has not yet been a similar research into the public profile of such measures, although some national reports mention that the public have been consulted or have been involved in procedures to reduce administrative burdens. The lack of similar research has been mentioned by working groups in various countries wanting to assess the impact of measures from this point of view (SCM Network, 2010).

The research in Slovenia included the private sector (businesses) and the public sector (civil servants). Questionnaires with the same content were used in order to determine any differences in understanding of the issue of administrative barriers and familiarity with measures in the field. The questionnaire comprised 13 interlinked questions. The first set of questions acquired basic data on the respondents (e.g. which part of the public sector there worked in or the size of business), followed 
by a question on respondents' familiarity with measures to reduce administrative burdens and the importance of these measures, as well as the respondents' participation in such measures. This was followed by questions on perceptions of administrative burden and definition of the most burdensome areas.

Both target groups were surveyed by e-mail. The survey of civil servants used questionnaires sent via e-mail to the central address of all central government and municipal bodies, from where the questionnaire was forwarded to the e-mail addresses of all employees. A total of 306 questionnaires were sent out. A total of 197 questionnaires were returned but only 90 had all questions answered, therefore the number of responses differs from question to question.

The electronic survey of businesses was conducted in April 2010 using a web-based program to carry out the survey of a sample of 600 businesses in five size-based representative groups: large, medium, small and micro-businesses, plus sole traders. A total of 125 respondents replied, though only 82 of these questionnaires were completely valid. The largest group of businesses that completed the questionnaire was the third category, which employs between 10 and 50 (37\%), i.e. small businesses, followed by category 2 (27\%), with up to 9 employees, while the smallest group was category 5 (2\%), businesses with over 250 employees. The structure of the final sample is therefore satisfactory given the structure of the overall population. The target person for the questionnaires was a general sector manager in large and medium-sized businesses and the director in small and micro-sized businesses and sole traders. If he was not available, the questionnaire could be completed by another appropriately-placed manager. Quota sampling was used so the sample was representative only within individual size groups, and also reflects the range of different economic activities and regional representativeness.

All results are given as either proportions (\%) or mean response values. In the following case, respondents individually scored possibilities on a rank from 1 to 5 , where 1 is always the lowest score (completely insignificant), and 5 is always the highest score (completely significant). 
Urška Milavec, Maja Klun

Familiarity with Measures to Reduce Administrative Burdens

in The Public and Private Sector in Slovenia

\subsection{Research results}

As stated in the introduction, the aim of the paper was to present research results assessing public and private sector familiarity with RAB measures and defining the areas of legislation that the sector deems causing the greatest administrative burden.

In response to the question of whether they had heard of the RAB project, only $38 \%$ of business respondents replied in the affirmative, while familiarity was higher in the public sector with $70 \%$ of responses in the affirmative. Only just over a third of private sector was therefore familiar with RAB measures, despite the fact that the majority of these measures were aimed at the private sector.

The next question was a control question linked to the first, asking whether respondents were familiar with the objectives and measures of the RAB project. Graph 1 indicates that even the private sector respondents who had heard of the project were not very familiar with it, as only $9 \%$ of business respondents gave their level of familiarity as good and not one gave their level of familiarity as very good. The more detailed question on familiarity with RAB objectives and measures was also poorer in the public sector, since only $40 \%$ assessed their level of familiarity as good or very good. Given that the project has been ongoing since Slovenia joined the $\mathrm{EU}$, the results indicate that the respondents in both sectors had a poor level of familiarity with the objectives and measures of the RAB project. For one third of private sector respondents familiarity with the (essential) content of the project was assessed as very poor, with $21 \%$ of public sector respondents gave the same response. 


\section{Graph 1: Familiarity with RAB project objectives and measures}

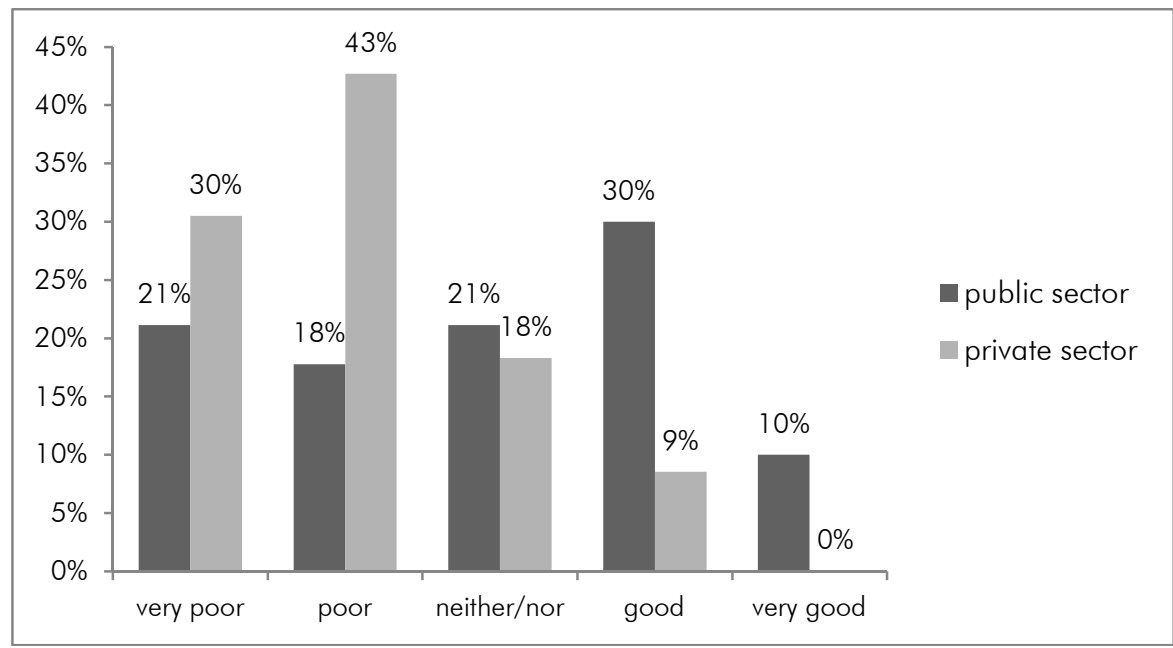

Source: survey

A poor level of familiarity with the objectives and measures of and the actual RAB projects as a whole is also seen in the low involvement of stakeholders in the project. In response to the question of whether respondents had submitted their own proposals for the reduction of administrative burdens, the majority responded in the negative. Proposals were only submitted by $3.7 \%$ of private sector respondents and $16.7 \%$ of public sector respondents.

The majority in the public and private sector (on average $63 \%$ of both groups) considered that the existing legislation represented a burden to their business or work. However, the response structure within the private sector indicates that this opinion is largely found in smaller businesses, since $38 \%$ of small and $29 \%$ of micro-businesses gave this opinion (responded very burdensome), while only $5 \%$ of large businesses gave the response "very burdensome". No business responded that the legislation was not a burden.

The research was also intended to verify whether the public and private sector had different levels of familiarity with RAB measures, particular those areas relating to reducing the administration costs of legislation. It is noteworthy that most respondents considered that costs had increased in the past three years. Despite this, some private sector respondents did report reductions in administrative costs, which means that some results had already been detected in practice (response 
Urška Milavec, Maja Klun

Familiarity with Measures to Reduce Administrative Burdens

in The Public and Private Sector in Slovenia

structure is given in Table 1). A more detailed analysis of the responses indicates that the reduction in administrative costs was only reported by micro and small-sized businesses and sole traders, while medium and large businesses did not give this response. Since most measures were actually aimed at small and medium-sized businesses these responses could have been anticipated. One can assess then, that some impacts of the RAB measures have already been noticed in the private sector, though to a small extent.

Table 1: Changes in administrative costs of regulations in past 3 years

\begin{tabular}{|l|r|r|}
\hline Changes in costs & Private sector (\%) & Public sector (\%) \\
\hline Major increase & 8.5 & 11.1 \\
\hline Increase & 64.6 & 51.1 \\
\hline Remained the same & 11.0 & 18.9 \\
\hline Reduction & 1.2 & 0 \\
\hline Major reduction & 1.2 & 0 \\
\hline Don't know & 13.4 & 18.9 \\
\hline
\end{tabular}

Source: Survey

The reasons for the increase are significant with regard to administrative costs. Most respondents in both sectors consider that costs are increasing due to continual regulatory amendments (Graph 2). This view was given by $67.1 \%$ of private sector respondents and $75.6 \%$ of public sector respondents. Unnecessary burdens on business administration are therefore often closely linked to adapting to new regulatory arrangements. The second most significant reason for increased costs according to the respondents was the excessive amount of regulation. This view was given by $63.3 \%$ of private sector respondents and $58.5 \%$ of public sector respondents. The reasons offered next by rank were regulatory complexity and lack of clarity in regulations. 


\section{Graph 2: Reasons for increase in administrative costs}

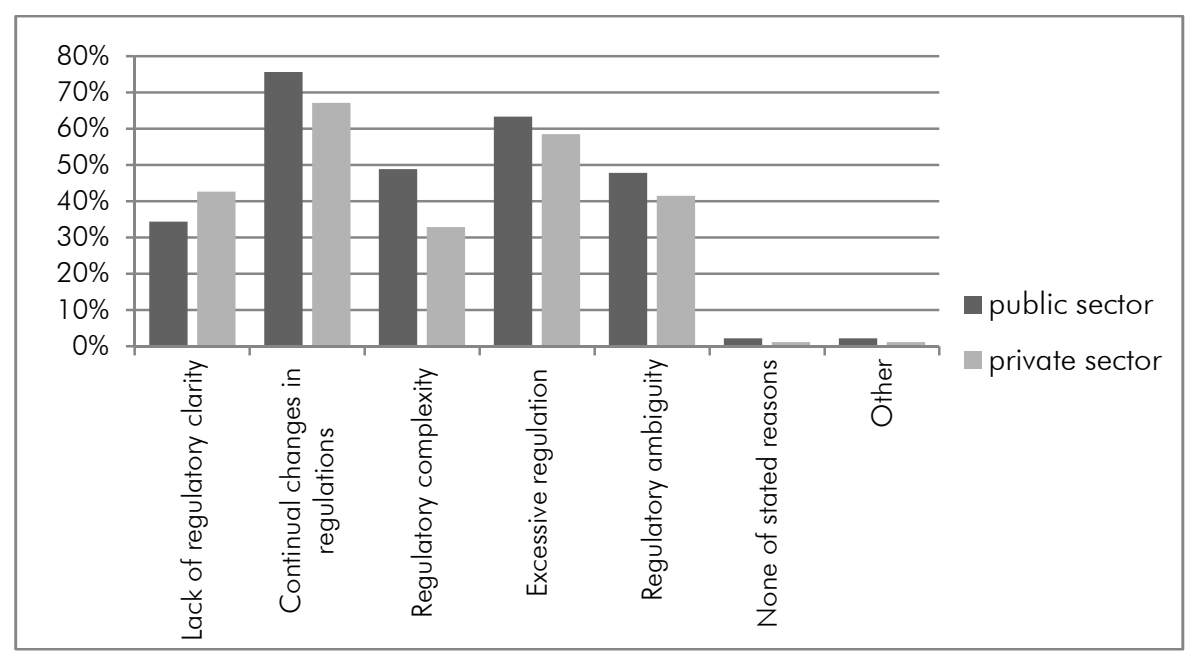

Source: Survey

Although RAB measures are transparently presented on the Ministry of Public Administration website, the research indicates that respondents' familiarity with them is relatively poor. More measures should be taken to increase their profile and hence improve awareness, primarily via appropriate private sector associations, better media promotion and progress reports. The greatest impact would be achieved if both sectors were far more involved in the project itself. The majority of respondents agreed with this, giving a high score to the statements that the interested parties should be directly included in projects addressing specific forms of regulation, and not just indirectly via self-initiative (i.e. sending proposals via the ministry website). The second highest scored proposal to improve the impact of the measures and hence also familiarity with them in both sectors was that the RAB project should be implemented in combined groups within individual "life-events".

The European Commission, and Slovenia likewise, have defined 13 priority regulatory areas as the most burdensome. The research was intended to investigate whether the two sectors perceive the administrative burden of individual areas of regulation differently and the area in which they want the most measures taken to ensure simplification (Graph 3). The most critical area according to the private sector was employment relations. That response was given by $62.2 \%$ of all private sector respondents. This has also been indicated by other research (see, for example, Klun and Slabe-Erker, 2008), therefore a systemic reduction of 
administrative costs in line with the SCM model was launched in Slovenia first in the field of employment law, with the adoption of the first action plan. The programme was set to conclude by the end of 2010. The second ranking area for private sector respondents was company law and annual financial statements. This view was expressed by $58.5 \%$ of businesses. The public sector also gave a high ranking to employment law (45.6\%), but identified the areas of public procurement as having the most burdensome legislation (62.2\%).

\section{Graph 3: Most burdensome areas}

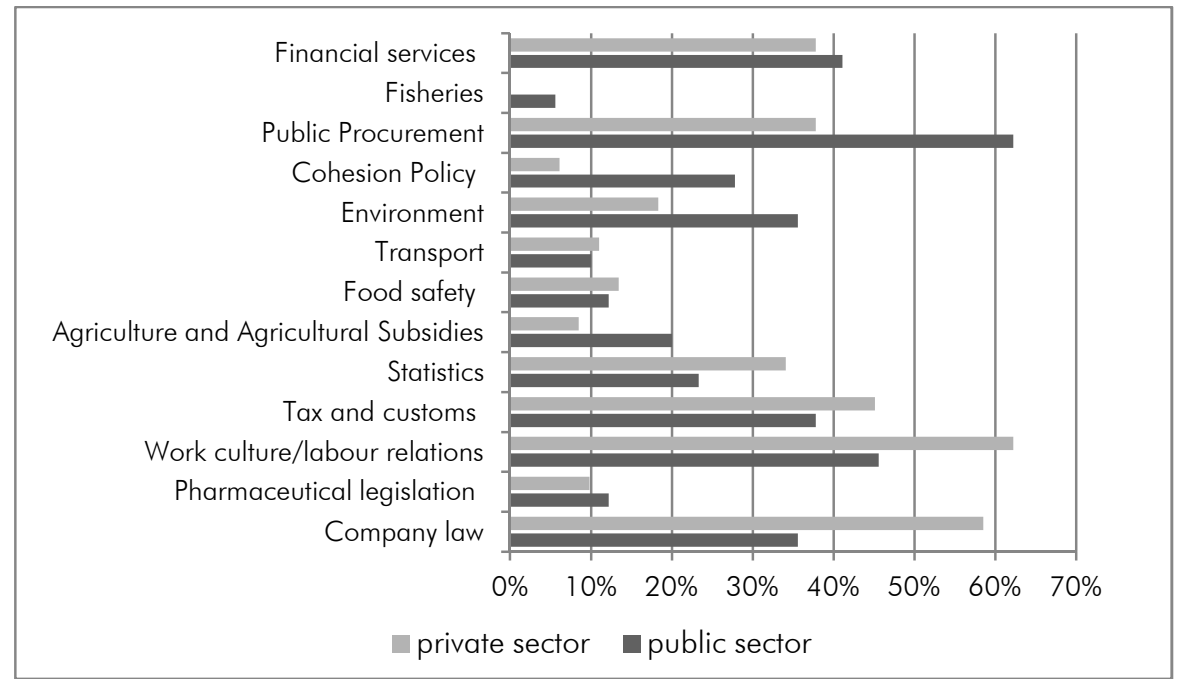

Source: Survey

The research results were as anticipated. The inflexibility of employment law is a well known problem in Slovenian legislation. The regulations in this field are very complex. The major procedures relating to employment, from advertising vacant positions, notifying appropriate agencies of employment, keeping relevant records, limited duration of fixed-term employment to high labour costs and minimum pay stipulations are all regulated by law in great detail. The restrictions are greater in the public sector given the many job specification systems, salary bands and lengthy recruitment procedures and other issues, particularly in central government. Competitive markets and inflexible regulations force the private sector to make use of restricted fixed-term employment, reorganisations linked exclusively due to staff turnover or artificial extensions of fixed-term employment contracts. All these measures lead to ineffective use of resources and reduce labour productivity. As expected, 
public procurement regulation is among the most burdensome for the public sector, since a great deal of its work is linked to public procurements, which require complex procedural management and preparation of quality tender dossiers and documentation. One must also emphasise the fact that the survey was carried out during a period in which amended public procurement regulations were being put into practice and that may have influenced the scores given. Although the new legislation has simplified some procedures, it has also introduced new requirements, such as compulsory training (licensing) and contract signing only after the deadline for appeals expires.

The reduction of administrative burdens in the two most burdensome areas of regulation for both sectors is an attainable objective, a fact supported by reports into the first measurements of administrative costs, principally employment legislation (for more see Klun et al., 2008). This has not yet been extended to public procurement regulations.

\section{Conclusion}

Since 2001 Slovenia has been working to simplify procedures and produce better legislation, both domestic and the regulations that form part of the EU acquis communautaire. The Ministry of Public Administration's website lists and explains the simplification methods available as part of the reduction of administrative burden: (i) removal, reduction, integration or improvement of regulations, (ii) simplification of processes within regulations, (iii) exchange of data within public administration, (iv) development of ICT solutions and services, and (v) providing better instructions and information. It is clear that administrative burdens in European and national regulations have been uncritically permitted to accumulate over the years. If the awareness of those writing regulations has not been adequately developed, or if they are not at least subject to control mechanisms, then administrative burdens will unavoidably accumulate. These are usually the result of bureaucratic thinking by people preparing regulations, a lack of regulatory impact analysis, neglecting the importance of how feasibly regulations can be put in practice, and the tendency for people within bureaucracies to increase their power of their organisation. The only solution to prevent administrative burdens from arising and to eliminate old burdens is a serious political commitment. Politicians have to lead and direct the public administration, and without such guidance it is very unlikely that patterns 
Urška Milavec, Maja Klun

Familiarity with Measures to Reduce Administrative Burdens

in The Public and Private Sector in Slovenia

of thought and behaviour will change. Frequent measurement of administrative costs and assessment of information quality and regulatory quality along with appropriately comparable results in terms of time, area and internationally comparability are needed to ensure that the right measures are applied to achieve relevance, effectiveness and durability.

The research indicated that the familiarity of various stakeholders in the RAB project with $R A B$ measures was still very poor, although results were starting to be noticed within the private sector. It is interesting that both sectors gave the same scores to reasons for administrative barriers occurring, while differently evaluating the most burdensome areas of regulation. The research results indicate that promotion of the RAB project must be more active, with greater participation of stakeholders in the project.

Urška Milavec has completed master's degree at the Faculty of Administration, University of Ljubliana in 2010.

Maja Klun, Ph.D. is associate professor at Faculty of Administration. Her main research fields are taxation, performance budgeting and performance measurement in public sector. 


\section{References}

- Brunetti, A., Kisunko, G. \& Weder B. (1998). How Businesses See Government. Responses from Private Sector Surveys in 69 Countries. Discussion paper no. 33. New York: World Bank.

- Chittenden, F., Kauser, S. \& Poutziouris, P. (2003). Tax regulation and Small Business in the USA, UK, Australia and New Zealand. International Small Business Journal (21), 93-115.

- Council of the European Union. (2005). Integrated guidelines: broad economic policy guidelines. Document 10667/05. Brussels: Council of EU.

- European Commission. (2007). Communication from the Commission to the Council, the European Parilament, the European Economic and Social Committe and Committee of the regions. Action Programme for Reducing Administrative Burdens in the European Union. COM (2007) 23. Brussels: EC.

- European Commission. (2009a). Impact assessment guidelines. SEC(2009)92. Brussels: EC.

- European Commission. (2009b). Communication from the commission to the council and the european parliament. Action Programme for Reducing Administrative Burdens in the EU Sectoral Reduction Plans and 2009 Actions. COM (2009) 544 final. Brussels: EC.

- European Commission. (2010). Enterprise and Industry. Better regulation. Action Programme for Reducing Administrative Burdens. Brussels: EC.

- Jallilian, H., Krkpatrick, C. \& Parker, D. (2007). The Impact of Regulation on Economic Growth in Developing Countries: A Cross-country Analysis. World Development (35), 87-103.

- Klun, M. \& Slabe-Erker, R. (2008). Ocena administriranja, povezanega s predpisi na področju zaposlovanja. Podjetje in delo (34), 640-650.

- Klun, M. \& Slabe-Erker, R. (2009). Business views of the quality of tax, environment and employment regulation and institutions: the Slovenian case. International Review of Administrative Sciences (75), 529-548.

- Klun, M. et al. (2008). Ovrednotenje administrativnih ovir za povečanje konkurenčnosti podjetii. Cilino raziskovalni program "Konkurenčnosł Slovenije 2006-2013". Zaključno poročilo. Ljubljana: Fakulteta za upravo in IER.

- Mandelkern (Group on Better Regulation). (2001). Final Report. Brussels: EC. 
Urška Milavec, Maja Klun

Familiarity with Measures to Reduce Administrative Burdens

in The Public and Private Sector in Slovenia

- Massey, C. (2003). The Impact of Business Compliance: Perceptions of New Zealand Firms. New Zealand Centre for Small \& Medium Enterprise Research, Massey University.

- Ministrstvo za javno upravo. (2009). -25\% - Program vlade Republike Slovenije do leta 2012. Ljubliana: MJU.

- OECD. (1997). The OECD Report on Regulatory Reform. Volume //: Thematic studies. Paris: OECD.

- OECD. (2001). Business' Views on Red Tape, Administrative and Regulatory Burdens on Small and Medium Sized Enterprises. Paris: OECD.

- OECD. (2009). Indicators of Regulatory Management Systems. Paris: OECD.

- $\quad$ Radaelli C. \& De Francesco F. (2007). Regulatory Quality in Europe Concepts, Measures and Policy Processes. Manschester: Manchester University Press.

- Radaelli, C. M. (2007). Whither Better Regulation for the Lisbon Agenda? Journal of European Public Policy (14), 190-207.

- Resolucija o normativni dejavnosti. Ur. I. RS, št. 95/2009 (Resolution on Regulatory Work, OGRS, no. 95/2009).

- SCM Network. (2010). Why reduce administrative burdens? Retrieved 1. 1. 2010, from http://www.administrative-burdens.com/default.asp? page $=239$

- Virant, G. \& Kovač, P. (2010). Reducing Administrative Burdens as Part of the "Better Regulation" Programme - the Case of Slovenia. Lex Localis (8), 369-393.

- Virant, G. (2010). Izboljšanje kakovosti regulacije - razvoj v Sloveniji. Uprava VIII(3), 113-134.

- Vlada Republike Slovenije. (2010). Načrt aktivnosti za skrajševanje postopkov in odpravo administrativnih ovir. Ljubljana: Vlada RS.

- Zakon o dohodnini. Ur. I. RS, št. $117 / 2006$ (Income Tax Act, OGRS, no $117 / 2006)$.

- Zatler, R. (2009). Odprava administrativnih ovir v publikaciji. Javna uprava (45), 287-299. 